\title{
Evaluating Management Efficiency of Korean Professional Baseball Teams using Data Envelopment Analysis (DEA)
}

\author{
Joon Ho Kang*, Young Han Lee* and Kwon Sihyeong** \\ *Seoul National University \\ 71 Rm. 201 San 56-1, Sillim-dong, Gwanak-gu, Seoul 151-748 Korea \\ kangjh@snu.ac.kr \\ ** The research institute for sport science, Seoul National University \\ 71 Rm. 315 San 56-1, Sillim-dong, Gwanak-gu, Seoul 151-748 Korea \\ [Received September 28, 2006 ; Accepted July 31, 2007]
}

\begin{abstract}
The purpose of this study is to evaluate management efficiency of professional teams in the Korean Baseball Organization by using Data Envelope Analysis (DEA). The professional baseball teams in Korea are in urgent need of efficient management as no teams are making profits and their financial deficits are growing. DEA is a technique to measure relative efficiency when coping with multiple inputs and multiple outputs. We implemented total player salary as input item and winning percent and total fan attendance as output item to evaluate 8 teams' management efficiency for the 2004 season. The analysis identified teams operating relatively efficient and teams that are not efficient. The result revealed that a team's efficiency score is not necessarily correlated to the final standings in the league. Rather, teams relatively mediocre sized outperformed the teams well-known for its financial abundance.
\end{abstract}

Keywords: data envelopment analysis (DEA), efficient team management, professional team sports

[International Journal of Sport and Health Science Vol.5, 125-134, 2007]

\section{Introduction}

In 1982, Korea's first major professional sport, baseball, was established followed by soccer in 1983 and basketball in 1997, consisting of 31 teams in total as of 2005. In 1999, pro-baseball, pro-soccer, and pro-basketball each earned approximately $\$ 140$ million ${ }^{1}$, $\$ 76$ million, and $\$ 52$ million, respectively, generating more than 250 million dollars combined (Kim and Lim, 1999). This figure represents 4.2\% of the entire size of the $\$ 6$ billion Korean sport market industry. In addition, recent corporate sponsorships on major pro-sports in Korea have significantly improved from title sponsorships to media sponsorships and player endorsements. Sponsorship deals for pro-baseball, pro-soccer, and pro-basketball in 2005 was $\$ 3.4$ million, \$3.6 million, and \$3.5 million, respectively (Choi, 2001). Meanwhile, media rights for 3 major sports in total expanded from, $\$ 8.4$ million in 2000 to $\$ 15.5$ million in 2003 and media services have also expanded with 4 exclusive major sport channels in cable and satellite TV with over 12 million cable viewers. Also, according to the report by Choi (2001), the 3 major sports have basked in a total of \$8 million in 2000 and nearly doubled its figures to $\$ 15$ million in 2003 for selling TV broadcasting rights.

Despite the development of Korean pro-sport market in general, there are, however, aspects such as fan attendance, TV rates, and pro-sport teams' financial status which are in a downslide. Pro-baseball's fan attendance has fallen from 540 thousand in 1995 to 270 thousand in 2000, while pro-basketball's TV rates fell from $9.5 \%$ in 1999 to

\footnotetext{
* This work was supported by Korea Research Foundation Grant funded by Korea Government

(MOEHRD, Basic Research Promotion Fund) (KRF-2005-003-G00050)

1 All currency in US dollar
} 
3.4\% in 2003 (Choi, 2001). Moreover, the Korean Sports Almanac $2005^{2}$ by the Korea Ministry of Culture and Tourism indicated that the average fan attendance in soccer stadiums has significantly diminished after the 2002 Korea-Japan World Cup event from 15,000 in 1999 and 13,000 in 2001 down to 9,000 in 2003 and 11,000 in 2004. Meanwhile, TV rates for pro-soccer has gone down from $3.8 \%$ in 2002 to $2.6 \%$ in 2003 . In the meantime, while it is typical in Korea for a conglomerate corporation to own a sport team and provide full financial support for its team operations, currently there are no individual pro-sport teams that generate profit out of the business. Choi (2001) denotes that, on average, the portion of the deficit is 3 times larger than the revenue. In 2002, the average financial deficit for a baseball team was 12.6 million dollars and in 2003 it was 12.7 million dollars. Among the total deficit $85 \%$ was covered by the parent company's financial support and $60 \%$ of the total expenditure came from player salary. The amount of financial deficit supported by the parent company and expenditure is growing in larger margin and the financial burden in operating a team is on the crisis as the industry prolongs. Nevertheless, the parent company is spending tremendous amount of money to support the team's financial deficit because the sole purpose of operating a pro-sport team is to fulfill the obligation of social vivification often pressured by the local consumers or the society. At one point, corporations were forced by the government to operate a pro-sport team in the early 1980's, when the militarist government took complete control of the sport in order to utilize for the betterment of its political party to gain lawful support from the nation and to consolidate its supremacy to maintain the regime (Lee, 2002). Naturally, the parent company seeks no other values in a pro-sport team other than a promotional tool to aid corporate product advertisement or brand exposure. As the pro-sport teams are losing fan base, the parent company's financial support becomes weak, thus the pro-teams are in urgent need of efficient management system.

Likewise to ordinary business entities that undergo company evaluation process, pro-sport teams must also be evaluated in the same sense. Otherwise, a sport team will not be left with any sort of competitive edge to survive within the competitive market. However, the traditional method of business entity evaluation based solely or heavily on its financial status is meaningless particularly to the professional sport teams in Korea because of its impotent ability to create any profit on its own. Therefore, a new approach is required that allows multiple inputs and multiple outputs measures that can be implemented other than net income or loss. Thus, the purpose of this paper is to evaluate managerial efficiency of the professional baseball teams in Korea by using the Data Envelopment Analysis technique.

\section{Production Functions and Efficiency in Professional Team Sports}

Unlike most industries, professional team sports' productivity of labor inputs can be directly measured with player performance variables. Output is also easily observable as team wins. In addition, Hadley, et al., (2000) support that professional team sport is a uniquely suited industry for empirical analysis of production and performance. Scully (1974) developed the first methodology that related sport teams' output to a variety of team input measures. This methodology has become the standard model for much of the subsequent work in similar areas. Medoff (1976), Sommers and Quinton (1982), Hill (1985), and Bruggink and Rose (1985) have variously utilized Scully's model. In the meantime, Zak, et al., (1979) and Scott, et al., (1985) used data from NBA (National Basketball Association) in the United States for their research and Atkinson, et al., (1988) have used data from the NFL (National Football League) for his study using Scully's model.

Porter and Scully (1982) employed a deterministic parametric approach with only two input variables to explain a baseball team's winning percent: the team's batting percent for hitter's input and ratio of strikeouts to base on balls for the pitcher's input. Later performance measurement by Scully (1994) was based on a production function in which winning percent depends on a single 'input' variable: the team's ratio of runs scored to runs allowed. Horowitz $(1994 a, b)$ also analyzed the performance of major league baseball managers using the same general

\footnotetext{
2 The Korean Sport Almanac (book) can be retrieved as electronic file via Korea Ministry of Culture and Tourism web site: http://www.mct.go.kr/open_content/common/search_view.jsp
} 
model. However, Ruggiero, et al., (1997) argue that the model by Porter and Scully (1982) is flawed because there are other important input variables that explain team output in MLB. Ruggiero prolongs his argument by denoting the ratio of runs scored to runs allowed is simply a proxy for the ratio of wins to losses. In essence, the study by Porter and Scully (1982) was based on basic single measurement not on the entire production relationship.

Other researchers have used a production function approach to address issues related to managerial performance without direct measurement. Kahn (1993) specifies a production function for MLB that includes team batting average, team fielding percent, team earned run average, and team stolen bases as well as the two Porter/Scully variables; however, he does not use this function to directly measure managerial performance. Instead, he uses a salary regression equation for managers to analyze managerial quality and team performance. Singell (1993) also examines the relationship between a manager's skills and the performance of his individual players. In 1995, Carmichael and Thomas conducted a study on rugby league football of England in attempt to formulate production function using true input data in the form of performance influencing variables, as well as performance-related inputs. The outcome of the analysis was individual teams' ranking according to its relative efficiency scores.

Contrasting viewpoints on the importance of the manager and coach emerge from the following literatures. At one extreme, Horowitz (1994a, b) concludes that managers are fungible inputs that make little difference in team performance. The alternative perceives the manager as a skilled decision-maker. Evidence from Porter and Scully (1982), Clement and McCormick (1989), and Ruggiero, et al., (1996) indicate that managers and coaches make significant contribution to their team's winning percent. Hadley, et al., (2000) measured the performance of NFL teams and head coaches by estimating a production frontier where the number of wins depends on offensive and defensive performance statistics. It employs a Poisson regression model and estimates the parameters using maximum likelihood. Porter and Scully (1982) estimated managerial efficiency of major league baseball on the level of the team. The study is established on the concept of frontier production function developed by Forsund and Hjalmarsson (1974) estimating efficiency of marginal revenue, the rate of change in managerial efficiency, and relative price efficiency. Porter and Scully (1982) has mentioned that the choice of baseball as for analysis is that output (winning percent) and input (player skills) are unambiguously measured and the production function is simply specified. The study concluded with a comment of the results indicating managerial skill in baseball contributes substantially to the production process.

In recent debates by the fans regarding which team is the best in the league, won-lost records are most often quoted; conversely, many coaches discuss less about won-lost records and more about their teams' playing up to their potential (Hofler and Payne, 1997). Hofler and Payne (1997) investigated how NBA teams play up to their potential using the stochastic production frontier model. The research provides efficiency measures for each of the 27 NBA teams for the 1992-1993 season and it examines efficiency in a cross-sectional analysis of all the teams while Zak, et al., (1979) examined the production efficiency of five professional basketball teams managerial efficiency. Sueyoshi, et al., (1999) on the other hand, proposed a new analytical approach for sport team (baseball) operational efficiency by combining Data Envelopment Analysis (DEA) with Offensive Earned-Run Average (OERA). The prominent feature of this research is that it can select a best performer among many baseball players and their ranking scores. Hass, et al., (2003) used DEA to measure relative efficiency of the German Bundesliga football teams. The study employed players' salary and coaches' salary as input variables and for output variables points awarded, average stadium utilization, and total revenues were selected. The result of this study displayed that efficiency scores are not correlated with the final rank in the 1999-2000 season.

\section{Methods}

As for the 8 Korean pro-baseball teams' management efficiency evaluation 'Frontier Analyst' from Banxia Software was utilized, which the logic and equation structure is based on Charnes, Cooper, and Rhodes' (1978) Data Envelopment Analysis (DEA) formula, also known as the CCR model. CCR model is a linear model that generates output 
$\mathrm{Y} 1$ from the input $\mathrm{X} 1$ assuming constant returns to scale (CRS) when assessing the Decision Making Unit $^{3}$ (DMU)'s efficiency. If an increase in a unit's input leads to a proportionate increase in its outputs then the unit exhibits CRS. This model advocates the ceteris paribus principle from the theories of microeconomics that no matter what scale the unit operates at, its efficiency will, assuming its current operating practices, remain unchanged. In this paper we have followed the external principle incorporated in the CCR model in regards of all things being equal. Therefore, we assume that an increase in a pro-baseball team's input will result in a proportionate increase in its outputs such as winning percentage or fan attendance, other things held constant. If a team does not produce output accordingly to input resource provided, then DEA picks out the team as inefficient because it is not operating appropriately to the CRS principle. In addition, Hong (2003) denotes that when the size of an input item for DMUs to be evaluated is comparatively the same then it is appropriate to use CCR model. In the case of pro-baseball teams in Korea, there are no teams that have extremely high or low input size. They are relatively in the same size and range among all teams ${ }^{4}$. The other ratio definition of efficiency that follows the condition of variable returns to scale (VRS) known as the BCC model named after Banker, Charnes, and Cooper (1984) is an extension of the CCR model. However, this model will not be covered thoroughly regarding conceptual theory or the mathematical formulation, since this model does not provide any impact to this study.

\subsection{Data Envelopment Analysis}

DEA, initiated by Charnes, Cooper, and Rhodes (1978), builds on the seminal paper by Farrel (1957) and extends the single-input to single-output engineering ratio approach to multiple-inputs to multiple-outputs without requiring a priory specification of weights and/or explicit delineation of assumed functional forms of relations between inputs and outputs. It also involves the use of linear programming method to construct a non-parametric piece-wise surface (frontier) over the data. DEA takes account of all the important factors that affect a DMU's performance to provide a complete and comprehensive assessment of efficiency. This is done by converting multiple inputs and outputs into a single measure of productive efficiency. By doing so DEA identifies those DMUs which are operating relatively efficient and those which are not. The outcome of the analysis is displayed in ratio for those making best use of their resources rated as being $100 \%$ efficient while the inefficient ones achieve lower scores. Interesting enough, it also identifies the units which are performing best and their operating practices can then be examined to establish a guide to "best practice" for others to benchmark and emulate.

It is imperative to clarify the fact that DEA is a measurement of relative efficiency and it provides a single measure of technical efficiency when coping with multiple inputs and multiple outputs. This is done via the basic principle assimilated in the following model.

$\operatorname{Max} \mathrm{TE}=$

$$
\begin{aligned}
& \text { s. t.: } \sum_{j=0}^{J} v n j Y n j n-\sum_{i=0}^{I} u n i X n i \leq 0 \quad \mathrm{n}=1,2, \ldots, \mathrm{N} \\
& \sum_{i=0}^{I} u n i X n i=1 \quad \text { uni, vnj } \geq \varepsilon>0
\end{aligned}
$$

Ynj : $n^{\text {th }}$ DMU's output $\mathrm{J}(\mathrm{j}=1,2, \ldots, \mathrm{J})$

$X n i: n^{\text {th }}$ DMU's input $\mathrm{I}(\mathrm{I}=1,2, \ldots, \mathrm{I})$

Let us denote that $n$ is the primary evaluation subject DMU. This DMU's efficiency will be TE which is the technical efficiency and we fixate the score not to exceed 1. The input item is indicated as $\mathrm{X} n i$ and output as Ynj. In addition, uni and $v n \mathrm{j}$ are the indications of input and output weights, respectively. $\varepsilon$ is the closest constant number to 0 and each DMU has at least one positive input and one positive output.

The dual problem is as follows:

$$
\operatorname{Min} \mathrm{Te}=\mathrm{a}_{\mathrm{n}}-\varepsilon\left(\sum_{i=0}^{I} S \bar{i}+\sum_{j=0}^{J} S \hat{j}\right)
$$

3 DMU (in this paper a baseball team) is a set of firm, group, team, or employee that is responsible for making decisions in a business environment to perform its business. (Ramanathan, 2005; Hong, 2003)

4 According to sport industry and DEA expert interviews conducted by the authors during the course of research, the input size given in this paper was concluded to be reasonable figures and size to be applied accordingly by the CCR model. 


$$
\begin{array}{ll}
\text { s.t.: } \sum_{n=1}^{N} \lambda n Y n j-S n \hat{j}=Y n j & \mathrm{j}=1,2, \ldots, \mathrm{J} \\
\text { - } \mathrm{a}_{\mathrm{n}} \mathrm{Xni}+\sum_{n=1}^{N} \lambda n X n i+S n \bar{i}=0 & \mathrm{i}=1,2, \ldots, \mathrm{I}
\end{array}
$$

$\operatorname{Sn} \bar{i}, \operatorname{Sn} \hat{j}, \lambda n \geq 0$

From formula (2), $\mathrm{a}_{n}$ is the technical efficiency of the relative amount of input resource used to produce certain amount of outputs compared to other DMUs. If $\mathrm{a}_{n}=1$ then it implies efficient DMU and if $\mathrm{a}_{n}<1$ then it implies that $1-\mathrm{a}_{n}$ amount of input resource is being wasted compared to other DMUs. The decision variable is $\lambda n$ and this is the factor that measures the $n^{\text {th }}$ DMU's contribution to the efficient frontier. S $n$ i and $\mathrm{S} n \mathrm{j}$ are the slack variables.

$$
\begin{array}{ll}
\text { Min PTE }=\beta n-\varepsilon\left(\sum_{i=0}^{I} S \bar{i}+\sum_{j=0}^{J} S \hat{j}\right) & \ldots \ldots \ldots \ldots . . . . . .(3) \\
\text { s.t.: } \sum_{n=1}^{N} \lambda n Y n j-S n \hat{j}=Y n j & \mathrm{j}=1,2, \ldots, \mathrm{J} \\
-\mathrm{a}_{\mathrm{n}} \mathrm{Xni}+\sum_{n=1}^{N} \lambda n X n i+S n \bar{i}=0 & \mathrm{i}=1,2, \ldots, \mathrm{I} \\
\sum_{n=1}^{N} \lambda n=1 \quad S n \bar{i}, S n \hat{j}, \lambda n \geq 0 &
\end{array}
$$

BCC named after Banker, Charnes, and Cooper (1984) is an extension of the CCR model when variable returns to scale is assumed. Alternative to constant returns to scale, if an increase in a unit's inputs does not produce a proportional change in its outputs then the unit exhibits variable returns to scale. This would mean that as the unit altered its scale of operations its efficiency would either increase or decrease.

BCC model supplements $\sum \lambda n=1$ to the CCR model to eliminate scale efficiency and establish pure technical efficiency (PTE)

\subsection{Data}

Data for the research, Korean professional baseball 2004 season, were collected from personnel of teams and league officials. As for controlling the number of input and output items to be chosen, DEA is best operated under the circumstance when the numbers of input and output items combined are selected reasonably to the number of DMU's (Hong, 2003). This is recommended because; relative to the number of DMU's to be evaluated, if too many input and output items are chosen then DEA will produce too many efficient DMU's. Hence, the comparison between efficient DMUs to other inefficient DMUs is meaningless because almost every DMU is efficient. Therefore, in this case only one input and two output items were chosen because of the limitation of data availability and number of teams. As for input item, since total expenditure figures are not opened to the public nor they are provided by the parent company, we took total player salary as a proxy, which consists more than 70\% (Choi, 2001) of the team's total budget. Also, number of total fan attendance was chosen to be one of the two output items because this feature represents total ticket sales (not provided by the teams). The other remaining output item was season winning percent since it represents the team's performance. The other potential input items that came across during the process such as number of players, coaching staffs, and front employees can be explained all in one by total player salary because the portion of coaching staffs and front employees numbers are insignificant, thus they were ignored.

\section{Results}

Table1 displays where individual teams rank in terms of management efficiency. As indicated in the table, among the 8 pro-baseball teams, LG Twins and Doosan Bears are the two efficiently managed teams while the remaining 6 teams are managing their teams less efficiently, in comparison to the two teams. Lotte Giants is very close in joining LG and Doosan, as they are located in the upper class; however, the team fell short on satisfying the total fan attendance section and requires to reduce player salary spending to (-) $2.6 \%$ for higher efficiency. In the meantime, Hanhwa Eagles have managed the team well enough to make it to the top four with a score of $87.15 \%$ and it does not seem too much of a burden to cut-off from the total player salary section, however, this team is the one that needs substantial improvement in total fan attendance as the team needs to increase over $200 \%$ in future seasons. The lower class starts with SK Wyverns which score is in the upper 70's. SK has a relatively high winning percentage with reasonable number of total fan attendance and has also completed the regular season 
Table 1 DEA Evaluation result Table

\begin{tabular}{|c|c|c|c|c|c|c|c|}
\hline Teams & $\begin{array}{c}\text { Efficien } \\
\text { cy score } \\
(\%)\end{array}$ & $\begin{array}{c}\text { Total } \\
\text { player } \\
\text { salary }\end{array}$ & $\begin{array}{l}\text { Target salary } \\
\text { (cut-off \%) }\end{array}$ & $\begin{array}{c}\text { Regular } \\
\text { season } \\
\text { winning \% }\end{array}$ & $\begin{array}{c}\text { Regular } \\
\text { season total } \\
\text { fan } \\
\text { attendance }\end{array}$ & $\begin{array}{l}\text { Target total } \\
\text { fan } \\
\text { attendance } \\
(\%)\end{array}$ & $\begin{array}{l}\text { Regula } \\
\text { r } \\
\text { season } \\
\text { standi } \\
\text { ngs }\end{array}$ \\
\hline Doosan Bears & 100 & 2,350 & - & 0.585 & 456,726 & - & 2 \\
\hline LG Twins & 100 & 2,672 & - & 0.432 & 620,865 & - & 6 \\
\hline Lotte Giants & 97.41 & 1,913 & $1,864(-2.6)$ & 0.464 & 307,537 & $\begin{array}{c}362,257 \\
(+18)\end{array}$ & 5 \\
\hline Hanhwa Eagles & 87.15 & 2,360 & $2,057(-12.8)$ & 0.512 & 128,387 & $\begin{array}{c}399,732 \\
(+211)\end{array}$ & 4 \\
\hline SK Wyverns & 77.08 & 3,038 & $2,342(-23)$ & 0.583 & 337,674 & $\begin{array}{c}455,164 \\
(+35)\end{array}$ & 3 \\
\hline Samsung Lions & 66.49 & 3,661 & $2,434(-33.5)$ & 0.607 & 195,872 & $\begin{array}{c}473,121 \\
(+141)\end{array}$ & 1 \\
\hline $\begin{array}{l}\text { Hyundai } \\
\text { Unicorns }\end{array}$ & 52.75 & 3,282 & $1,731(-47)$ & 0.431 & 129,036 & $\begin{array}{c}336,493 \\
(+160)\end{array}$ & 7 \\
\hline Kia Tigers & 46.28 & 3,402 & $1,575(-53.7)$ & 0.392 & 155,881 & $\begin{array}{c}306,045 \\
(+96)\end{array}$ & 8 \\
\hline
\end{tabular}

Note: Salary in thousand (USD)

in 3rd place; nevertheless, the player salary spent is over exceeding when compared to the peers from the upper 4 teams. Although it is not much, SK still needs to reduce their cost in player salary in order to score higher or increase winning percentage.

Samsung finished number 1 in the regular season; naturally they have the highest winning percentage. Samsung spends tremendous amount of money to acquire the most skilled players and coaching staffs in the field and so far they have been successful, however, they were not successful in efficient team management as they failed in gathering fans to the stadium. Hyundai Unicorns is among the lowest tier of the pack with a relatively low DEA score of $52.7 \%$. They have one of the lowest winning percentage and number of fan attendance among the teams and finished second to last in the regular season, but rather large amount of player salary spent is the reason for the Unicorns to be at such disappointing status. In order for the Unicorns to be successful in managerial efficiency, their cost would have to be cut down to (-) $47 \%$ as well as $160 \%$ increase in number of fan attendance. It is obvious to notice the reason why Kia Tigers came in last in this evaluation. Kia Tigers' cost is among the highest while their winning percent is the worst and fan attendance is $3 \mathrm{rd}$ from the bottom. The number of fan attendance does not appear to be too bad, relatively; however, there are others that produce more or less the same amount of fan attendance and win games with a similar amount of cost.

As indicated in Figure 1 the efficient frontier X1 is the border line of production efficiency, while the teams on this line are considered to be efficient, the remainders inside the line are the ones inefficient. For example, consider the case of SK Wyverns which does not lie on the frontier. By improving the performance of the team it can move towards the frontier along OA and make contact with the frontier at point $\mathrm{B}$ which is the hypothetical team that is a composite of LG Twins and Doosan Bears. Hence, efficiency of SK Wyverns is measured by the ratio $\mathrm{TE}$ (technical efficiency) $=\mathrm{OA} / \mathrm{OB}$ which is represented by Y1 in the figure. In other words, $\mathrm{Y} 1$ is the transparent line that directs the inefficient teams toward efficiency. In addition, during the course of DEA analysis, 'peer group' is created which is also called as 'reference set'. The reference set is the set of efficient branches to which the unit has been most directly compared when calculating its efficiency score. In the meantime, an inefficient unit's reference set contains the efficient units which have the most similar input/output orientation to itself and they should provide examples of good operating practice for it to emulate (Haas, 2003). Also, the efficient team that intersects with line Y1 can be considered to be the benchmark team to its nearest peer (Hong, 2003). In this paper, LG Twins 


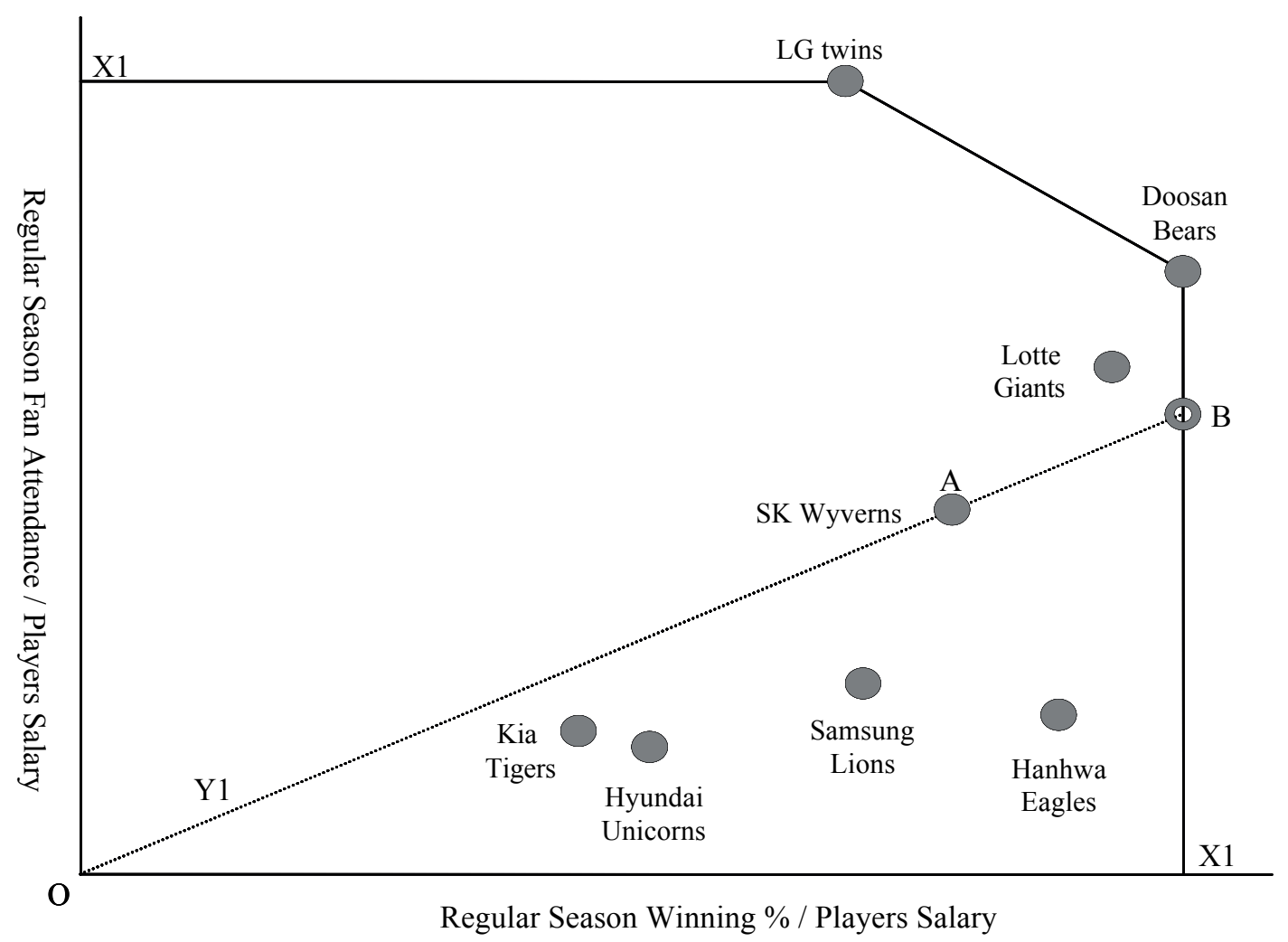

Figure 1 Frontier Plot Diagram

and Doosan Bears are the reference teams that can be emulated by inefficient teams in registering their best performance. In the case of SK Wyverns, Y1 is drawn until it meets point $B$ and the closest efficient team is Doosan Bears, thus SK Wyverns can optimize its management efficiency by benchmarking Doosan Bears' input/output orientation. Moreover, the remaining six inefficient teams have the similar input and output structure to Doosan Bears' since all of the inefficient teams are near Doosan Bears when line $\mathrm{Y} 1$ is drawn over each respective teams towards the frontier line X1.

\section{Discussion}

If we were to evaluate a sport team merely based on its financial status and its results from the games, then the rule of thumb is that the rich gets richer and the poor gets poorer. A team with tremendous deal of financial power will always buy-off the most profound players into becoming a franchise player and this in turn would get the victory from the games and the fans. Hence, the poor teams stand no chance against the rich teams in outperforming them. However, DEA allows managers to optimize multiple inputs and outputs to manipulate a team's management performance to reach its maximum potential. DEA also allows the managers to plan ahead for the next season given the target inputs and outputs to be enhanced. As in the case of LG Twins, the team had finished 6th in the regular season with little over .40 game winning percentage but still managed to get on top in the evaluation. The Twins only needed to spend the fourth least amount of resource to get the most number of fan attendance. This implies that a team with no high paid star players and less winning games is still capable of satisfying the fans to visit the stadium. It is possible that comprehensive marketing tactics or building loyal fan base activities have played a significant role in the case of LG's success.

The other efficient team was Doosan Bears which the team's input and output structure is slightly different from LG Twins. The Bears fall in the same category as $L G$ in spending relatively less player salary, however, Doosan Bears had finished 2 nd to Samsung Lions in the regular season and also had high winning percentage of .588 , which is also 2nd to Samsung. Ironically, the number of fan attendance was also the second highest in the league. From the frontier plot diagram you can locate Doosan to be the model figure for all the inefficient 
teams to benchmark for higher efficiency. Thus, the Bears managed themselves to be efficient in every aspect. A good coach may have got the players to maximize their physical abilities and mentalities or it can be guessed that they have a way of keeping the fans entertained. We may not know at this point with limited information given, however, it is clear that Doosan Bears have managed and utilized their limited resource well enough to generate abundance in both sides of the outputs.

Among the 8 pro-baseball teams, Samsung Lions has the highest amount of player salary spent and Lotte Giants has the lowest. Although Lotte is in 3rd place being efficient, behind Doosan and LG, it may not be a good sample to follow because it seems the only factor that boosted the Giants up to 3rd place is their low player salary. They finished the regular season with a poor standing and their game winning percentage and number of fan attendance is ordinary. The other bad sample in particular is Samsung Lions which spends great deal of money to bring in high profiled players only to focus on winning the games. As a sport team, as far as winning is concerned, Samsung Lions is the best team out in the field, however, when optimization factor is involved, this team is wasting its resources too much to get the job done; especially when winning games is not a significant factor in bringing the fans to the stadium, as in the case of the Lions.

Probably, the most excellent quality feature about evaluating sport teams by DEA is providing information on the quest for greater efficiency. It allows managers and decision makers to take account of all the important factors that affect a team's overall performance to provide a complete and comprehensive assessment of efficiency. As in our case, pro-baseball, managers would have better knowledge and insight over their teams' status by DEA evaluation, eventually leading them to make more refined decisions for optimizing an organization. Moreover, DEA analysis can be applied not only on baseball teams merely in Korea, but also on other sport teams such as rugby, soccer, basketball, and so on in other countries. In addition, evaluating individual teams is based on the usage of DEA analysis on a micro level, as in our case; however, it can also be utilized in analyzing leagues and sport organizations based on a macro sense; as well as utilizing private and participant sport organizations such as fitness centers, local amateur teams, health care centers, and sport facilities.

\section{Conclusion}

Korea's pro-sport industry is now into its third decade commencing from the establishment of pro-baseball league in the early 1980's and one may consider this span of time is long enough for the industry to grow, expand, and develop both in quality and quantity. So far, it can be perceived that the quality of the game and player skills have continuously improved, however, the operation aspect of the team have yet to improve since there is still lack of fan attendance and significant amount of financial deficit among all pro-sport teams in Korea. In addition, this phenomenon is not only a problem to the Korean sport industry but also to the Asian sport market especially Japan and China. This phenomenon is more in effect nowadays when Western sport is more and more penetrating into our living rooms, stadiums, and shops. Currently, Asian countries are under the circumstance where they need to face direct competition with the Western countries in the sport industry. Consequently, the sport managers of the three mainstream Asian countries, Korea, Japan, and China must alter their mind set in order to create highly efficient team operations. This would promote effective cost control and efficient team management, eventually leading teams to generate higher values. As a result, the sport teams in Asian countries will become more possible in not only competing shoulder to shoulder with the Western teams, but can also be more aggressive and active in exporting players and developing sport derived products.

\section{References}

Atkinson, S. E., Stanley, L. R., \& Tschirart, J. (1988). Revenue sharing as an incentive in an agency problem: an example from the national football league. Rand Journal of Economics, 19(1), 27-43.

Banker, R. D., Charnes, A., \& Cooper, W. W. (1984). Some models for estimation technical and scale inefficiencies in Data Envelopment Analysis. Management Sciences, 30 (9).

Bruggink, T.H., \& Rose, D.R., Jr. (1990). Financial restraint in the free agent labour market: Players look at strike three. Southern Economic Journal, 56(4), 1029-1043.

Carmichael, F., \& Thomas, D. (1995). Production and efficiency in team sports: as investigation of rugby league football. Applied Economics, 27, 859-869.

Charnes, A., Cooper, W. W., \& Rhodes, E. (1978). Measuring the efficiency of decision making units. European Journal of Operational Research, 2(6). 
Choi, J. W. (2001). Solutions for sports industry development. Retrieved from Samsung Economic Research Institute Website: http://www.seri.org/db/dbReptV.html? g_menu $=02 \&$ s_menu $=0201 \&$ pubkey $=$ db20010401

Clement, R. C., \& McCormick, R. E. (1989). Coaching team production. Economic Inquiry, 27(2), 287-304.

Farrel, M. J. (1957). The measurement of productive efficiency. Journal of the Royal Statistical Society Series A, 120, 253-290.

Forsund, F., \& Hjalmarsson, L. (1974). On the measurement of productive efficiency. Swedish Journal of Economics, 76, 131-153.

Hadley, L., Poitras, M., Ruggiero, J., \& Knowles, S. (2000). Performance evaluation of national football league teams. Managerial and Decision Economics, 21, 66-70.

Hass, D. J. (2003). Productive efficiency of English football teams-A data envelopment analysis approach. Managerial and Decision Economics, 24, 403-410.

Hass, D. J., Kocher, M. G., \& Sutter, M. (2003). Measuring Efficiency of German football teams by Data Envelop Analysis. Austria: University of Innsbruck.

Hill, J. R. (1985). The threat of free agency and exploitation in professional baseball: 1976-1979. Quarterly Review of Economics and Business, 25(4), 68-82.

Hofler, R. A., \& Payne, J. E. (1997). Measuring efficiency in the National Basketball Association. Applied Economics Letters, 55, 293-299.

Hong, B. Y. (2003). Measuring Efficiency of Department Stores by DEA. Korean Accounting Information Review, 21, 309-327.

Horowitz, I. (1994a). Pythagoras, Tommy Lasorda, and me: on evaluating baseball managers. Social Science Quarterly, 75, 187-194.

Horowitz, I. (1994b). On the manager as principal clerk. Managerial and Decision Economics, 15, 413-419.

Kahn, L. (1993). Managerial quality, team success, and individual player performance in Major League Baseball. Industrial and Labor Relations Review, 46, 531-548.

Kim, S. H., \& Lim, D. S. (1999). Development strategy of professional sports industry. Seoul, Korea Institute for Industrial Economics and Trade.

Korea Ministry of Culture and Tourism. (2005). Korean sports almanac 2005. Seoul, Chongno: Keimyung: Author.

Lee, J. W. (2002). A study on the sport policy of the fifth government of the republic of Korea. Unpublished doctoral dissertation, Seoul National University, Korea.

Medoff, M. H. (1976). On monopsonistic exploitation in professional baseball. Quarterly Review of Economics and business, 16(2), 113-121.

Porter, R., \& Scully, G. W. (1982). Measuring managerial efficiency: the case of baseball. Southern Economic Journal, 48(3), 642-650.

Ramanathan, R. (2005). Operations assessment of hospitals in the sultanate of Oman. Oman: Sultan Qaboos University, College of Commerce and Economics.

Ruggiero, J., Hadley, L., Ruggiero, G., \& Knowles, S. (1997). A note on the Pythagoras theorem of baseball production. Managerial and Decision Economics, 18, 335-342.

Scott, F. A., Long, J. E., \& Sompi, K. (1985). Salary vs. marginal revenue product under monopsony and competition: the case of professional basketball. Atlantic Economic Journal, 13(3), 50-59.
Scully, G. W. (1974). Pay and performance in major league baseball. American Economic Review, 64, 915-930.

Scully, G. W. (1994). Managerial efficiency and survivability in professional team sports. Managerial and Decision Economics, 15, 403-411.

Singell, L. (1993). Managers, specific human capital, and firm productivity in Major League Baseball. Atlantic Economic Journal, 21, 47-59.

Sommers, P. M. \& Quinton, N. (1982). Pay and performance in Major League Baseball: the case of the first family of free agents. Journal of Human Resources, 17(3), 427-436.

Sueyoshi, T., Ohnishi, K., \& Kinase, Y. (1999). A benchmark approach for baseball evaluation. European Journal of Operational Research, 115, 429-448.

Zak, T. A., Huang, C. J., \& Siegfried, J. J. (1979). Production efficiency: the case of professional basketball. Journal of Business, 52(3), 379-392. 


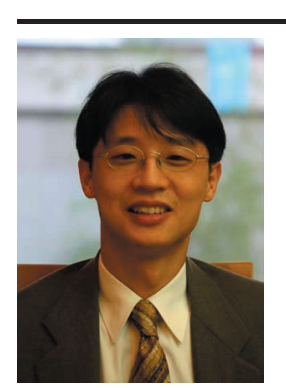

\section{Name:}

Joon Ho Kang

\section{Affiliation:}

Seoul National University

\section{Address:}

71 Rm. 201 San 56-1, Sillim-dong, Gwanak-gu, Seoul 151-748

Korea

\section{Brief Biographical History:}

1998-2001 Assistant professor in sport management, Department of Kinesiology, University of Connecticut

2001-2003 Assistant professor in sport management, Department of Physical Education, Seoul National University

2003-Associate professor in sport management, Department of Physical Education, Seoul National University

2004- Director, Center for Sport Industry, Seoul National University

\section{Main Works:}

Journal Publications:

- Kang, J. (2002). A structural model of image-based and utilitarian decision-making processes for participant sport consumption. Journal of Sport Management, 16(3), 173-189.

- Kang, J. \& Kim, J. (2004). Analysis of perceptual maps for spectator sport service and other leisure services. Korean Journal of Sport Science, 15(2), 90-102.

- Kang, J (2004). The role of self-esteem in initiating physical activity in consumption situations. Journal of Sport Management, 18(3), 255-273.

- Park, S. \& Kang, J. (2005). A study on sporting prize indemnity insurance as complementary salary tool for professional basketball players. Korean Journal of Sport Science, 16(2).

- Kang, J. (2005). The concept and the categorization of the sport industry. Korean Journal of Sport Science, 16(3), 118-130.

- Kim, K., \& Kang, J.(2006). The influence of consumption emotion and satisfaction on intention to re-attend professional soccer. Korean Journal of Sport Science, 17(3), 126-135.

- Kim, K \& Kang, J. (2007). A study on market segmentation for the target marketing of Jeju United FC. Korean Journal of Sport Science, 18(2), 22-31.

Books:

- Kang, J., \& Cho, S. (2003). Sport Media. Seoul Olympic Sports Promotion Foundation.

- Shin, Y., \& Kang, J. (2003). Professional Sport Business. Seoul Olympic Sports Promotion Foundation.

\section{Membership in Learned Societies:}

- Member, North American Society for Sport Management

- Member, Korean Alliance of Health, Physical Education, Recreation and Dance

- Member, Korean Society for Sport Management

- Editorial board member, Journal of Sport Management, published by North American Society for Sport Management, U.S.

- Editorial board member, International Journal of Sport Finance,

- Editorial board member, International Journal of Sport and Health Science, published by Japan Society of Physical
Education, Health and Sport Sciences, Japan

- Editorial board member, International Journal of Applied Sports Science, published by Korea Sport Science Institute, Korea 